\title{
Proceeding
}

Supplementary Issue: Winter Conferences of Sports Science. Costa Blanca Sports Science Events, 22-23 March 2021. Alicante, Spain.

\section{Approaches to motor learning: Cognitive approach versus ecological dinamyc one}

\author{
GAETANO RAIOLA $\checkmark$, FELICE DI DOMENICO \\ Department of Human, Philosophical and Education Sciences, University of Salerno, Italy
}

\begin{abstract}
The aim is to deepen the knowledge on the scientific evidence between the biomedical and pedagogical part and on the differences of the two approaches commonly used for teaching / learning processes: the cognitive and ecological-dynamic approach on one's own characteristics and specific paradigms. The retrieval of scientific literature took place through the use of specialized web research on: PubMed, Google Scholar, Scopus, PMCfreearticle, CrossRef by PRISMA method. Motor learning is the stabilized execution of a given movement, executive technique, or gesture. It means that in the face of a number of repetitions most are performed correctly. Cognitive approach places the person at the centre of the teaching / learning process, neglecting the inferences that the surrounding environment produces. Ecological-dynamic approach, which considers motor coordination as an organization emerging from the peripheral constraints of the system rather than from central control structures, is defined as ecological, since it does not consider the aspects of motor coordination within the individual but, more generally, the complex interaction between the individual and the environment and the circular relationship between perception and action. The characteristics and paradigms of two approaches highlight two opposite ways to motor learning with an unsolved problem on which one is correct to use in physical education and sports performance.
\end{abstract}

Keywords: Prescriptive teaching; Heuristic learning; Didactics exercise; Educational praxis; Affordances.

Cite this article as:

Raiola, G., \& Di Domenico, F. (2021). Approaches to motor learning: Cognitive approach versus ecological dinamyc one. Journal of Human Sport and Exercise, 16(3proc), S1491-S1505. https://doi.org/10.14198//hse.2021.16.Proc3.65

Corresponding author. Department of Human, Philosophical and Education Sciences, University of Salerno, Italy. http://orcid.org/0000-0002-7659-1674

E-mail: raiolagaetano@libero.it

Abstract submitted to: Winter Conferences of Sports Science. Costa Blanca Sports Science Events, 22-23 March 2021. Alicante, Spain.

JOURNAL OF HUMAN SPORT \& EXERCISE ISSN 1988-5202.

(c) Faculty of Education. University of Alicante.

doi:10.14198/jhse.2021.16.Proc3.65 


\section{INTRODUCTION}

Those involved in the teaching of motor and sports activities must, explicitly or implicitly, define and continuously redefine their criteria for making methodological-didactic decisions. The most rational criteria for making such decisions are offered by theories of movement based on scientific results. However, one wonders what to do when different scientific results endorse different theories of movement, as is the case with the two main approaches to motor control and learning: the cognitive and the ecological-dynamic, which are based on different theoretical disciplines, partially explain aspects different types of motor control and learning and lead to substantially different didactic methodological conclusions. The approaches to motor learning fall within the qualitative aspects of motor-sports research and are contrasted, due to the reduced methodological rigor of the experimental research design, to the quantitative aspects which, on the other hand, enjoy a consolidated and shared positive meaning of the reference scientific community (Raiola, 2014).

The consequence of this dualistic separation for the teaching of motor and sports activities is evident. In sports activities, where the achievement/exceedance of the biological limit of human performance is pursued, biomechanical and energy quantitative study prevails. The result is a scientific, objective approach to the training of what are called conditional performance assumptions. In educational motor activities, where objectives for the development of motor coordination are pursued, qualitative observation of the form of movement prevails: the result is a poorly objective approach to the teaching of what are called coordinating assumptions of motor performance. This dichotomy reduces the amount of scientific production tending to experimental investigation to increase knowledge of motor and sports learning mechanisms. As a result of this problem, the study aims to bring out the most recent scientific evidence and organize the result according to a clear and exhaustive dualistic scheme (prescriptive versus heuristic).

The aim is to deepen the knowledge on the scientific evidence between the biomedical and pedagogical part and on the differences of the two approaches commonly used for teaching / learning processes: the cognitive and ecological-dynamic approach on one's own characteristics and specific paradigms.

\section{METHOD}

The research was carried out through a careful consultation of the scientific literature: book chapters on sports performance and sports training methodology and scientific articles published between 1923 and 2020. The retrieval of scientific literature took place through the use of specialized web research on: PubMed, Google Scholar, Scopus, PMCfreearticle, CrossRef by PRISMA method. The most recent articles and the most influential authors were considered. The following keywords have been entered into the search engines: Motor learnings, heuristic learnings, prescriptive teaching, sports skills, motor and sports development, performance. These terms have been combined with each other and with other keywords, namely: sports training, physiology, neurophysiology, competition and performance, needs for disability and no disability.

\section{RESULTS AND DISCUSSION}

24 scientific articles and 6 book chapters out of a total of over 100 publications were considered. Publication selection criteria were used: the chapters were extracted from training methodology books; the articles are in English, published in scientific journals.

Table 1 lists all the sources included in the review, highlighting, for each author, the subject of the publication and the source. 
Table 1. List of sources.

\begin{tabular}{llll}
\hline & Authors & Topics & Source \\
\hline 1 & Adams 1971 & Motor learning & Scientific article \\
2 & Bernstein 1966 & Motor behaviour & Book chapter \\
3 & Bernstein 2014 & Motor behaviour & Book chapter \\
4 & Chow et al. 2007 & Motor learning & Scientific article \\
5 & Chow 2013 & Motor learning & Scientific article \\
6 & Davids et al. 2008 & Motor learning and control & Book chapter \\
7 & Dhawale et al. 2017 & Motor learning & Scientific article \\
8 & Diamond 2013 & Executive functions & Scientific article \\
9 & Gibson 2014 & Ecological approach & Book chapter \\
10 & Graser et al. 2019 & Heuristic learning & Scientific article \\
11 & Haken et al. 1985 & Dynamic patterns & Scientific article \\
12 & Hassler 1978 & Motor control & Scientific article \\
13 & Hastie et Siedentop 1999 & Ecological paradigm & Scientific article \\
14 & Heft 1989 & Ecological approach & Scientific article \\
15 & Keele 1968 & Performance & Scientific article \\
16 & Kelso 1994 & Coordination dynamics & Scientific article \\
17 & Komar et al. 2019 & Motor behaviour & Scientific article \\
18 & Lee et al. 1991 & Prescriptive teaching & Scientific article \\
19 & Magill et Hall 1990 & Ecological approach & Scientific article \\
20 & Merbah et Meulemans 2011 & Motor learning & Scientific article \\
21 & Newell et al. 1989 & Motor Behaviour & Scientific article \\
22 & Raiola 2014 & Motor control and learning skills & Scientific article \\
23 & Renshaw et al. 2010 & Sports skills & Scientific article \\
24 & Renshaw et al. 2016 & Ecological dynamics & Scientific article \\
25 & Renshaw et Chow 2019 & Constraints-led approach & Scientific article \\
26 & Smith et Wrisberg 2008 & Motor learning and performance & Book chapter \\
27 & Smith et al. 2018 & Motor control and learning & Book chapter \\
28 & Tomporowski et al. 2015 & Sports skills & Scientific article \\
29 & Warren 2006 & Motor and sports development & Scientific article \\
30 & Wolpert et Kawato 1998 & Motor control & Scientific article \\
\hline & & &
\end{tabular}

\section{Motor learning}

Motor learning is the stabilized execution of a given movement, executive technique, or gesture. It means that in the face of a number of repetitions most are performed correctly (according to the ideal biomechanical model). The movement allows the: conservation and development of the organism; the increase in the amount of useful information; the increase in the performance motor potential of the individual.

Motor learning is a process which, through the first execution or repetition, both assisted by the knowledge acquired from experience, leads to the acquisition of the first form of new skills or consolidation (stabilization of movement) and improvement of skills already possessed. In the field of physical and sports education, the main ways of approaching control and motor learning are the cognitive and ecological-dynamic approaches. 


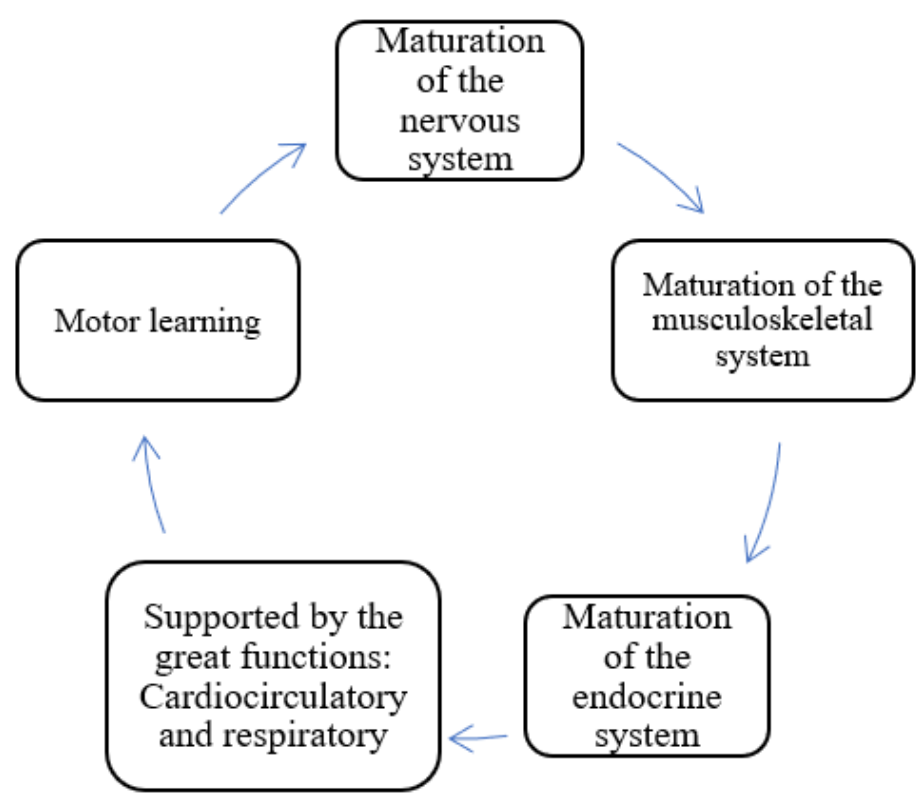

Figure 1. The development of advanced motor skills.

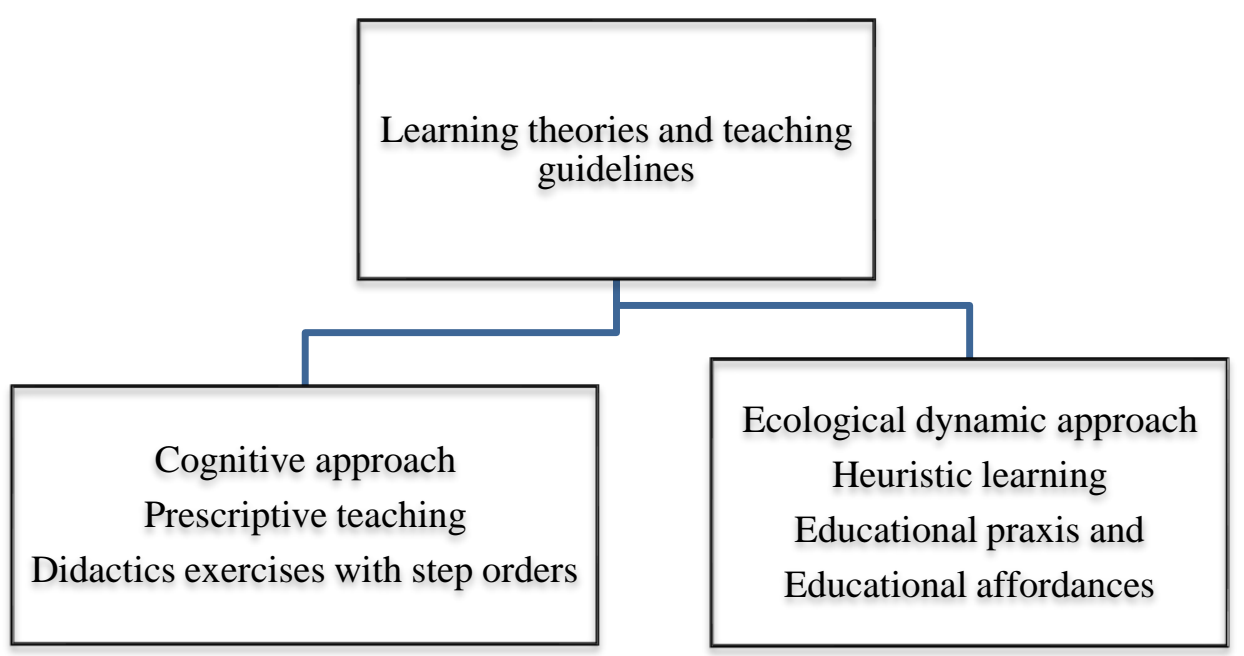

Figure 2. Motor learning approaches.

\section{Cognitive approach}

This approach places the person at the centre of the teaching / learning process, neglecting the inferences that the surrounding environment produces. It has the basis of the theories of the mind in the behaviourist paradigm with the stimulus-response algorithm and in the cognitivist paradigm in the version that sees innatism that is projected towards the construction of knowledge (Constructivism) also in relation to cultural phenomena (Culturalism). It is substantiated with the application of existing schemes for phylogenetic and ontogenetic evolution. The human being has at the cerebral level, a series of motor programs, or sequences of commands which, at the level of the central nervous system in the most ancestral part (Bridge, Bulb and Mesencephalon) are activated automatically thanks to the complex command generated voluntarily and which it is topologically located in the cerebral cortex (Hassler, 1978). The complex phenomenon of 
interaction between voluntary acts and the use of motor programs makes it possible to improve performance or to provoke new learning. Therefore, enforceability and frequency are the basis of learning.

If the movements are slow enough, the information from the sense organs and proprioceptors can be used by the system to correct the movement during its execution. It is the closed-loop motor control model (Adams 1971). The shortest form of closed loop control is the monosynaptic reflex loop. The longer the movement execution time, the greater the possibility of using the wider feedback motor control circuits, ranging from polysynaptic reflexes to intentional movement regulation based on conscious sensory information, such as acquire through focal vision (Schmidt \& Wrisberg 2008). If, on the other hand, the movement time is shorter than the duration of the conduction of nerve impulses along the proprioceptive afferent fibres, which are the fastest form of motor afference, we speak of motor control in an open circuit: the movement, to be performed, must be programmed completely a priori, and cannot be corrected during its execution (Keele, 1968). The central programs also include the specifications for the preliminary postural adjustments aimed at maintaining balance during movement, as well as the commands needed to modulate these adjustments by reflex way. Evidence in favour of the existence of motor programs that define a priori the structure of movements has been provided by various types of experiments. For example, as the complexity of the movement increases, the latency between the start signal and the start of the movement also increases, because the time required for programming the movement increases (Graser et al., 2019).

Among the theories of motor control by program, the one currently most accredited is the theory of generalized motor programs (Schmidt et al., 2018). This theory makes it possible to overcome the problem of the huge amount of motor programs to be stored over the course of life if the program / movement ratio were 1:1. In fact, it is believed that a generalized program contains motor commands that define the deep structure common to an entire class of movements (e.g. throws or jumps), while the specific surface characteristics of each single movement, belonging to any given class, are defined from time to time through a parameterization process (Wolpert \& Kawato, 1998). The invariant characteristics of generalized motor programs are the relative duration of the individual functional phases of the movement, the relative strength, i.e., the acceleration impressed in each individual phase of the movement, and the sequential order of muscle contractions. Two movements belong to the same class if the deep characteristics coincide, regardless of the diversity of surface characteristics which are, respectively, the total duration of the movement, the absolute force and the activated effectors. By executing in diversified form several movements belonging to the same class of actions, such as e.g., a launch in variety of execution time, amplitude and direction, the parameterization process is exercised. This process leads to the consolidation and improvement of the generalized program thanks to the formation of the motor scheme, which is a scheme of rules on the relationship between the different types of parameterization and their effects on motor execution.

The formation of the motor pattern explains why it is possible to perform a movement never performed before. This is a new executive variant of a generalized motor program, which can be performed by extrapolating from the motor scheme the parameters suitable for the execution of the new movement. The cognitive theory of generalized motor programs has provided both an "economic" solution to the problem of storing motor programs, and a convincing explanation of the phenomenon by which one is able to perform movements never performed before. However, it is unable to explain other phenomena observable in learning. First of all is the problem of executive variability, highlighted by Bernstein (1966). If, as the centralist theories of motor programs affirm, motor execution were the direct resultant of a structured set of motor commands stored centrally, executive variability should tend to zero with the progress of learning thanks to the progressive improvement of the motor programs. To explain the persistence of a certain degree of executive variability even after a very high number of repetitions, it is necessary to shift the focus from the central programming 
of movements to the variety of physical constraints imposed on motor coordination by the periphery of the body and by the environment (Magill \& Hall, 1990; Warren, 2006).

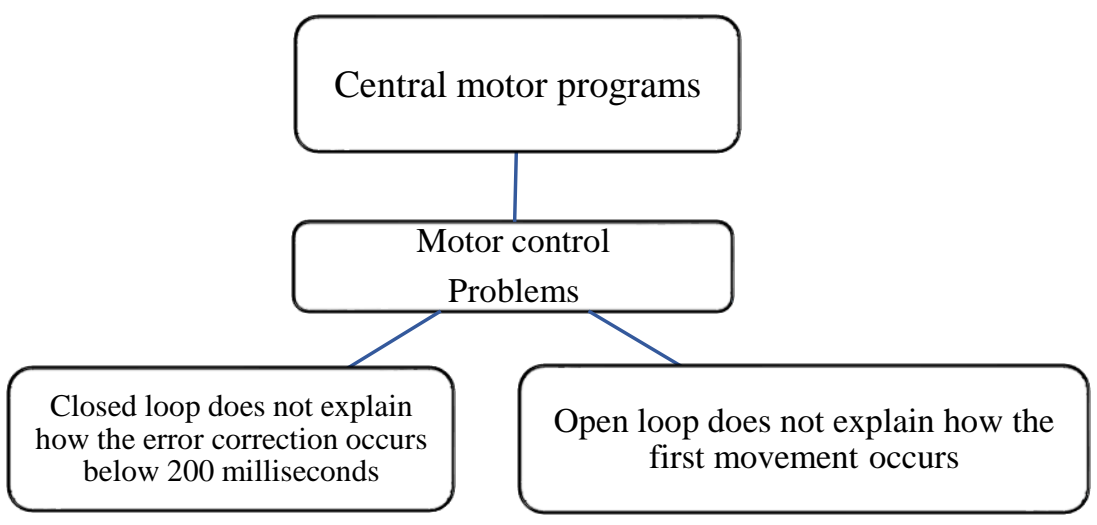

Figure 3. Limits of the motor control in cognitive approach.

The cognitive theory of motor learning derives directly from the integration of the cognitive theories of open loop (through generalized motor programs) and closed loop (through feedback) motor control theory. The direct consequence of cognitive theory in didactic applications is a prescriptive approach (Tomporowski et al., 2015). For each exercise there are multiple repetitions, checking and correcting errors by the teacher. The teacher prescribes exercises to the student in order to stabilize and refine the executive motor models with respect to the theoretical biomechanical model using the motor programs that everyone possesses by virtue of their ontogenetic background (Haken et al., 1985).

Table 2. Prescriptive teaching characteristics.

\begin{tabular}{|l|}
\hline Prescriptive Teaching \\
\hline Oral explanation and simulation of movement \\
\hline Exact repetitions of movement \\
\hline Detailed explanation of predetermined rules \\
\hline Time period control \\
\hline Role control \\
\hline Correction of the error by feedback \\
\hline Provide pre-established materials and tools \\
\hline Establish the sequence of movements to be performed \\
\hline Well-defined spaces \\
\hline
\end{tabular}

The teacher explains in detail the exercise (teaching tool) and orders with the command (start), the sequence (the movements that come before and those that come after), the timing (the duration of each phase of the sequence), the achievement of the goal (result) and the monitoring and verification of motor learning. The teacher must apply in a programmed way the means and methods of didactic facilitation suitable for a given subject, for a specific task, in a particular context. 


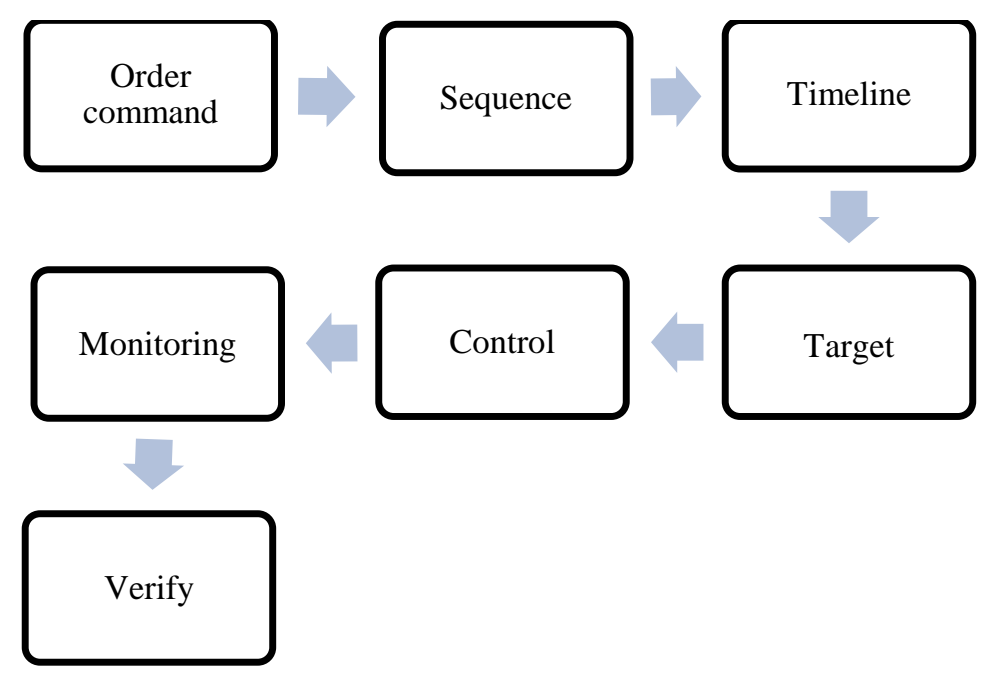

Figure 4. Phases of prescriptive teaching.

If the motor task is particularly complex, partial practice techniques are applied to reduce its difficulty. The action is fragmented / segmented and then progressively recomposed. The prerequisite for partial exercise or other teaching facilitation techniques to be effective and facilitate learning is that the profound structure of the generalized motor program is not altered, which is updated with the exercise. Fractioning consists, for example, of having the movements of the lower and upper limbs exercised separately, and then recombining them, once automated, in a simultaneous form (Merbah \& Meulemans, 2011). Finally, a movement can be exercised in a simplified form by reducing its speed of execution or the demands for precision, such as using larger tools or targets. This technique is also effective only on condition that certain slowdown or imprecision limits are not exceeded.

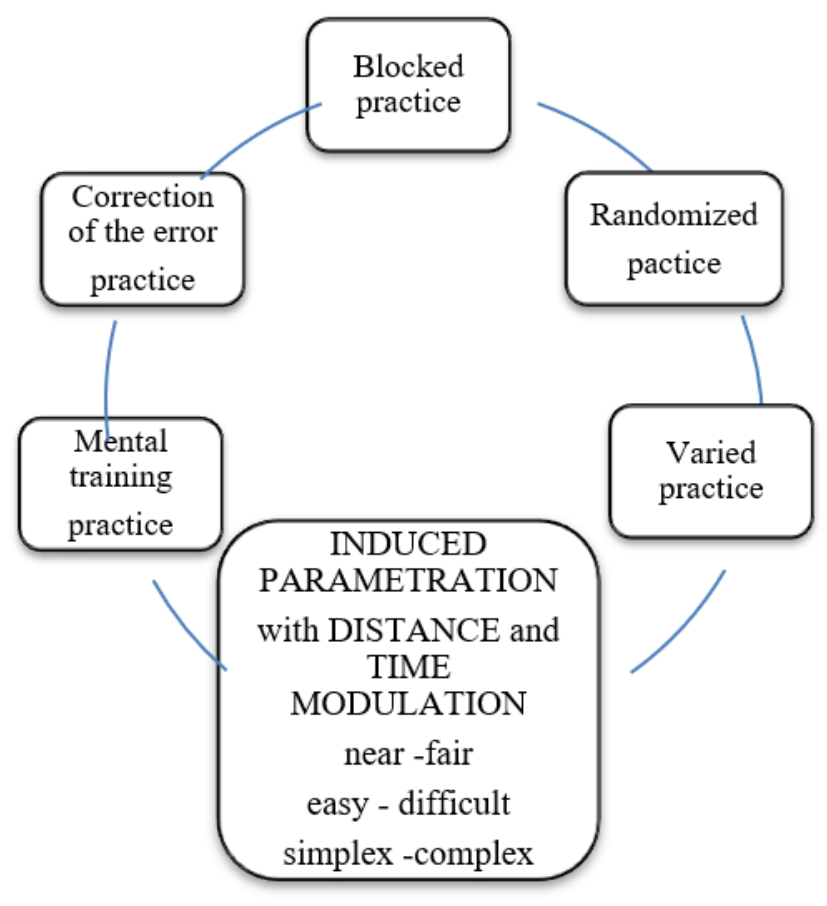

Figure 5. Prescriptive teaching in training techniques into the Cognitive approach. 
Randomized and varied exercises are other exercise techniques that are justified in the theory of generalized motor programs (Wulf, Schmidt 1988). The randomized exercise consists of performing various motor tasks without a precise sequential order, minimizing consecutive repetitions of each individual task: e.g., alternating jumping and throwing tasks. This exercise technique probably enhances learning for two reasons: because it allows the student to better perceive the different peculiarities of the individual tasks (Komar et al., 2019) and because it requires the student to exercise the selection of the motor program with each repetition, which is not necessary if the repetitions of the same task are performed consecutively, in block, before moving on to the next task (Lee et al., 1991).

The varied exercise, on the other hand, consists in having several movements belonging to the same class performed, i.e., several executive variants of the same generalized motor program: e.g., throwing a ball at different speeds, distances, and directions. This exercise technique enhances learning probably because it allows the learner to exercise the parameterization of the generalized motor program, i.e., the definition of variable parameters in motor execution, which is not the case if you repeatedly exercise the same movement in constant form, without changing its speed, amplitude, and direction (Kerr, Booth 1978). The randomized and the varied exercise can be combined: for example, launch tasks can be carried out at different speeds and distances by alternating them, in randomized sequence, with jump tasks of different amplitude and directions. In this way, both the ability to select different generalized motor programs and the ability to parameterize them are simultaneously strengthened, enhancing the relationship between the values attributable to the parameters and the resulting motor results.

Another technique to enhance the learning experience is to provide the learner, during learning, with additional information to those that derive from the execution of the movement (kinaesthetic afferences). That is, to add to the intrinsic feedback the extrinsic one (Magill \& Hall, 1990). This is verbal or visual information about the correctness of the movement and the result achieved (knowledge of the results) or about the executive quality of the movement (knowledge of the performance). The methodological-didactic problem is to define what and how much information to provide, at what time, with what frequency and with how much precision. Cognitive psychology provides evidence that endorses the improved effectiveness of extrinsic feedback if it is given a few seconds late from the end of motor execution, with progressively decreasing frequency as the level of learning progresses, and only when the pupil's performance deviates from that desired by exceeding certain limits of fault tolerance (Swinnen et al. 1990). The theory of generalized motor programs has direct methodological-didactic implications on the choice of which information to provide with feedback. This choice depends on the type of error made by the student: if he got the execution wrong because the relative duration of the individual functional phases of the motor gesture is different from the desired one, it means that he selected the wrong motor program. If, on the other hand, the learner got the execution wrong because the movement is overall too wide or too short, but the duration of the phases is correct, it means that he has selected the correct program, but has attributed to the variable parameters' inadequate values (Newell et al., 1989). In general, it is good to first provide feedback to correct the program selection error (e.g., "Slow down the oscillation phase" and/or "accelerate the output phase") and only secondarily to provide feedback to correct the parameterization errors. If the selected motor program is the right one, the feedback related to the variable parameters is very advantageous for learning, because it enhances the training of the motor pattern, that is, it helps the student to discover the rules that allow him to perform with precision, at first sight, variants of a given motor gesture never performed before.

Finally, cognitive psychology suggests enhancing the learning experience through indirect exercise techniques that prepare for the practical improvement of a given skill without implementing it: mental training and mental representation (Feltz, Landers 1983). Mental training consists in thinking about the cognitive and 
procedural aspects of the action, while the mental representation consists in imagining the performance of a motor action. With these techniques, the cognitive components of motor control are exercised, that is, those processes of information processing that integrate and support motor programming in the strict sense, such as attentional processes, decision-making processes, and processes of anticipation of the probable result of motor action.

\section{Examples of didactic exercises with prescriptive teaching}

Training the set shot in basketball.

1) Perform a set shot: perform a set shot with elbow that looks at the basket, distension of the body, the wrist moves forward.

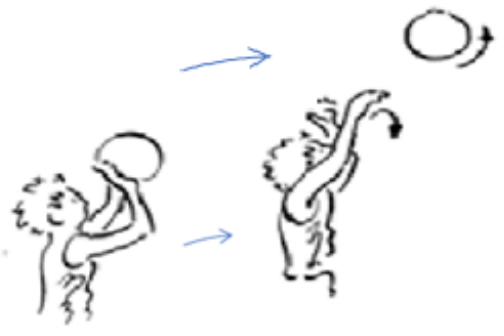

Figure 5. Set shot.

2) Perform a reasoned shot: the students dribble near a circle, stop inside it at one or two times and shoot for the basket.

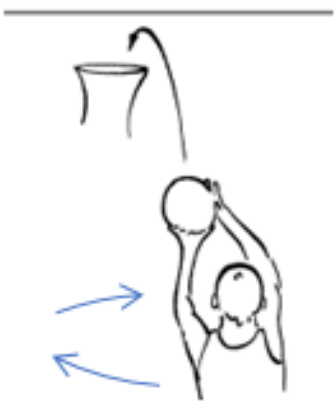

Figures 6. Make a reasoned shot.

3) Exercising set shots: 2 students dribble and pass the ball under the basket, next to other couples. They take set shots to the basket when the basket is free.

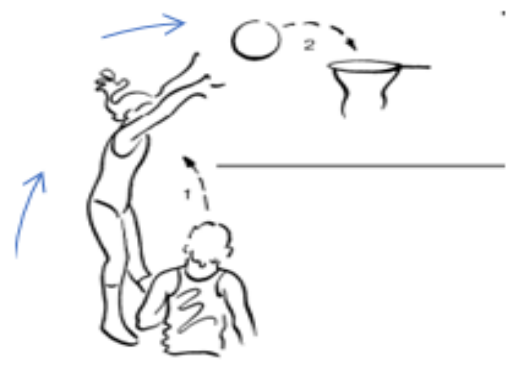

Figures 7. Practice set shots. 
4) Training for running shooting in basketball.

Running shot (right-hand finish with right hand):

- Perform a dribble with your right hand so that the ball touches the ground at the same time as the support of the left foot.

- Grab the ball little in front of the body.

- Right support.

- Start the ascensional movement with the left.

- Flexion of the right knee in the detachment.

- Completely stretch out the right arm that leaves the ball at maximum elevation.

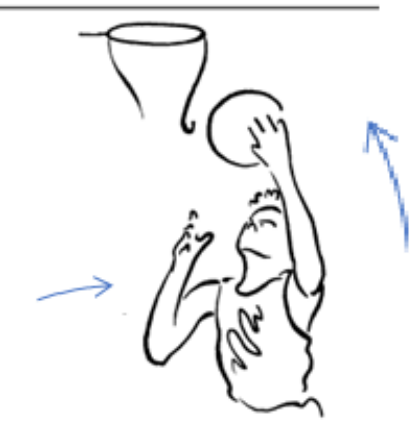

Figures 8. Running shot.

\section{Ecological-dynamic approach}

The approach which considers motor coordination as an organization emerging from the peripheral constraints of the system rather than from central control structures is defined as ecological, since it does not consider the aspects of motor coordination within the individual but, more generally, the complex interaction between the individual and the environment and the circular relationship between perception and action (Kelso,1994). This is an interdisciplinary approach born from the intersection of the following theoretical currents (Summers 1998): Bernstein's cybernetic perspective on motor coordination (Bernstein, 2014), the ecological psychology of Gibson's direct perception (Gibson, 2014), the theory of nonlinear physical dynamics applied to self-organization in biological systems (Chow et al., 2007) and synergetic applied to the formation of functional motor units for intersegmental coordination (Heft,1989). Bernstein, for one, highlighted a central problem of motor coordination, closely linked to the concept of variability in the reproduction of coordinated movements: the problem of degrees of freedom of movement, which to this day is called "the Bernstein problem". Persistent executive variability, even at high levels of automatization, in repetitions of the same movement, depends on the fact that the motor system has to cope with a huge number of degrees of freedom deriving from the properties of the neuromuscular system and the characteristics of the motor tasks and the environment in which they are carried out (e.g., mechanical properties of the muscles, gravitational factors). A key concept within the theory of dynamical systems is that of self-organization: to arrive at the execution of coordinated movements we move from randomized phases to ordered phases of movement organization thanks to the self-organizational properties of the system (Kelso 1994). A typical example of this selforganization is that of the asynchronous movement of the hands on a surface: increasing the frequency of movement until it exceeds a certain threshold takes place a spontaneous transition from phase opposition to movement in the phase of the two hands. This phenomenon is interpreted as a self-organizational tendency of the system towards stable forms of coordination. 
Bernstein was the first to highlight a central problem of motor coordination, closely linked to the concept of variability in the reproduction of coordinated movements: the problem of the degrees of freedom of movement, which is still called "Bernstein's problem". Persistent executive variability, even at high levels of automatization, in the repetitions of the same movement, depends on the fact that the motor system has to cope with a huge number of degrees of freedom deriving from the properties of the neuromuscular system and the characteristics of the motor tasks and the environment in which they are carried out (e.g., mechanical properties of the muscles, gravitational factors). A key concept within the theory of dynamical systems is that of self-organization: to arrive at the execution of coordinated movements we move from randomized phases to ordered phases of movement organization thanks to the self-organizational properties of the system (Kelso 1994). A typical example of this self-organization is that of the asynchronous movement of the hands on a surface: increasing the frequency of movement to exceed a certain threshold, a spontaneous transition occurs from the movement in phase opposition to the movement in phase of the two hands (D'Isanto et al., 2019). This phenomenon is interpreted as a self-organizing tendency of the system towards stable forms of coordination. So, the main differences between the cognitive approach and the ecological-dynamic are the following: the cognitive approach is structural, it hypothesizes hierarchically structured central motor control mechanisms that regulate movement in a programmed way. The ecological-dynamic approach, on the other hand, is phenomenological, it describes laws and principles on which the motor control system is based, which is heterarchic and has self-organizing properties. It excludes sequencing and timing linked to the stimulus-response mechanism that has at its centre the analysis and processing of the data and the design of the movement. It presents the paradigm of the complexity of the action with non-sequential and non-timed dynamics (Davids et al., 2008). It considers the elements and dynamics in the environment according to a natural and hardly manipulable order where the principle is adaptation as a priority form of learning. There is a full and extensive interaction with the environment, things, people, and rules. The limit of the theory is that there is no repetition of movement equal to another in terms of space and time because it is impossible to measure two equal movements. There is a high complexity of the neuromuscular system that does not allow to identify the priority elements from the secondary ones. We have not yet arrived at a mathematical formula that objectively establishes the relationship between the design part of the movement (mind) with neurological elements and the executive one with neurophysiological and physiological elements of movement.

In the ecological-dynamic approach, exercising does not always mean repeating the same solution to a given task but repeating the process of solving the task itself repeatedly (Hastie \& Siedentop, 1999). Didactics in the ecological-dynamic approach is aimed at stimulating the emergence of spontaneous (heuristic) solutions to motor problems, thus exploiting executive variability, i.e., implementing a process of searching for motor solutions that passes through the continuous variation of motor gestures (Dhawale et al., 2017). According to the ecological approach, learning means being able to progressively find the best motor solution to a given task in a given context. In heuristic learning, the teacher must assist the student in the autonomous search for motor solutions. If the learning task is too complex, constraints should not be imposed on the student by indicating in a prescriptive manner how to simplify motor execution, but constraints must be applied to the environment (Renshaw \& Chow, 2019).

It shuns the homologation of learning indiscriminately for everyone because, considering attitudes, it develops in a unique and unrepeatable way for each one with executive particularities in the executive motor models that consider the anthropometric structural characteristics and the different nervous functions (Diamond, 2013). Its main function is self-regulation and allows the free expressiveness of movement in interaction with others and with the limits of the context. It has the main function of guiding learning activities in self- and hetero-observation. The teacher / instructor / coach has a modest role which has the task of facilitating activities, ensuring safety, and developing the maximum motor potential for everyone in 
harmonious educational action. It has the basis in motor control of the degrees of freedom and motor imagination. In the ecological approach, since it is a question of finding the best solutions to motor tasks each time, the executive variability is not seen as a limiting factor, but as an inherent property, an index of the nonlinear interaction of the system with the constraints imposed by the organism, the task, and the environment during the search for motor solutions (Chow, 2013). Spontaneous solutions are stimulated by the teacher to respond to the problems that arise by optimizing executive variability and, therefore, urging the search for suitable solutions with the adoption of techniques borrowed from psychology and the change in the surrounding environment. It implements educational practices characterized by self-regulation of facilitated and safe activities with observation activities (car and hetero to be used for briefing and debriefing). Delivery is the educational tool and provides for the modification of the rules and the structuring of the game environment with the maximum relationship and cooperation on the part of the students/athletes (Renshaw et al., 2010; 2016).

Table 3. Characteristics of heuristic learning

\begin{tabular}{|l|}
\hline Heuristic Learning \\
\hline Self-determination and self-organization with high free grade cooperation \\
\hline Free expression on variability of movement in order to techno-tactical choose \\
\hline Changing the rules to enlarge the participation \\
\hline Self- and hetero-observation as a learning guideline for monitoring. \\
\hline Roles established inside the group \\
\hline Free guided discovery \\
\hline Provide different materials and tools according to group self determination \\
\hline Indicate the goal without prescriptions about sequence and timeline of performed action. \\
\hline Modification and adaptation of environment aligning enlarge participation \\
\hline
\end{tabular}

\section{Examples of didactic exercises with heuristic learning}

1) Hit in the centre 2 with 1: two students throw a ball through a hoop held high by a partner.

- Groups decide when to rotate in positions.

- We are looking for original forms of throwing and catching.

- The group comes up with their own ideas on how to modify the game

- The player in the centre moves slowly, forcing the other two to constantly adjust their position.

- Each group must travel a certain distance by performing as many throws as possible across the circle.

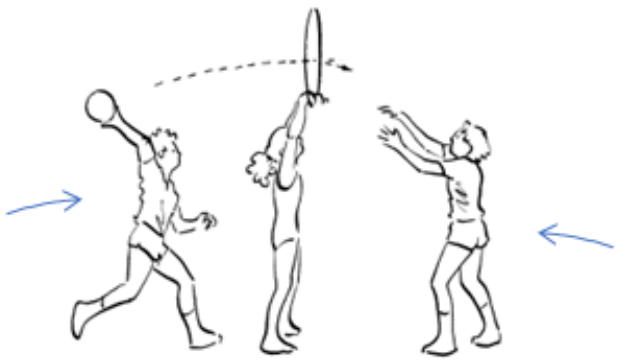

Figure 9 . Hit the centre 2 with 1

2) Ball Steal 3 vs 2 :

Three students pass the ball while 2 others try to touch or intercept it.

- The five decide for themselves when to switch positions. 
- Groups invent other rules for scoring points.

- Points are scored only by respecting agreements made previously: passages with rebound, passing between two poles or over a rope.

- The groups play autonomously; in case of conflict the teacher intervenes.

3) Create the game yourself!

- We divide the class into two groups.

- We show them the name of the business: The eagle and the chicks.

- We indicate which physical activity should be more present: running.

- We provide further information: the activity must be in a group and the tools present in the gym must be used, half of the pitch must be occupied.

- We give the two groups a set time (e.g., $20 \mathrm{~min}$ ) to design the game and establish the rules and the different roles.

- The goal of this activity is to stimulate creativity and freedom of expression starting from a game that involves motor activity.

Didactic strategies to enhance heuristic learning, i.e., to stimulate the emergence of "spontaneous" solutions to motor problems, they are based on a single principle: exploiting executive variability, that is, implementing a search process for motor solutions that passes through the continuous variation of motor gestures.

\section{CONCLUSION}

The characteristics and paradigms of two approaches highlight two opposite ways to motor learning with an unsolved problem on which one is correct to use in physical education and sports performance. First, they are suggested in both a formal and informal educational context. Secondly, both must be calibrated according to the overall goal. Thirdly, it is necessary to suggest different educational / didactic paths according to the specific needs of the person in the double student-athlete version. Finally, to research in order to International classification of functioning (ICF) of OMS to aim the physical and sport activity for all without conceptual barriers.

\section{REFERENCES}

Adams, J. A. (1971). A closed-loop theory of motor learning. Journal of motor behavior, 3(2), 111-150. https://doi.org/10.1080/00222895.1971.10734898

Bernstein, N. (1966). The co-ordination and regulation of movements. Pergamon Press; [1st English ed.].

Bernstein, N. A. (2014). Dexterity and its development. Psychology Press. https://doi.org/10.4324/9781410603357

Chow, J. Y., Davids, K., Button, C., Shuttleworth, R., Renshaw, I., \& Araújo, D. (2007). The role of nonlinear pedagogy in physical education. Review of Educational Research, 77(3), 251-278. https://doi.org/10.3102/003465430305615

Chow, J. Y. (2013). Nonlinear learning underpinning pedagogy: evidence, challenges, and implications. Quest, 65(4), 469-484. https://doi.org/10.1080/00336297.2013.807746

Davids, K., Button, C., \& Bennett, S. (2008). Dynamics of skill acquisition: A constraints-led approach. Human Kinetics.

Dhawale, A. K., Smith, M. A., \& Ölveczky, B. P. (2017). The role of variability in motor learning. Annual review of neuroscience, 40, 479-498. https://doi.org/10.1146/annurev-neuro-072116-031548 
D'Isanto, T., D'Elia, F., Raiola, G., \& Altavilla, G. (2019). Assessment of sport performance: Theoretical aspects and practical indications. Sport Mont, 17(1), 79-82. https://doi.org/10.26773/smj.190214

Diamond, A. (2013). Executive functions. Annual review of psychology, 64, 135-168. https://doi.org/10.1146/annurev-psych-113011-143750

Gibson, J. J. (2014). The ecological approach to visual perception: classic edition. Psychology Press. https://doi.org/10.4324/9781315740218

Graser, J. V., Bastiaenen, C. H., \& van Hedel, H. J. (2019). The role of the practice order: A systematic review about contextual interference in children. PloS one, 14(1), e0209979. https://doi.org/10.1371/journal.pone.0209979

Haken, H., Kelso, J. S., \& Bunz, H. (1985). A theoretical model of phase transitions in human hand movements. Biological cybernetics, 51(5), 347-356. https://doi.org/10.1007/BF00336922

Hassler, R. (1978). Striatal control of locomotion, intentional actions and of integrating and perceptive activity. Journal of the neurological sciences, 36(2), 187-224. https://doi.org/10.1016/0022510X(78)90082-5

Hastie, P., \& Siedentop, D. (1999). An ecological perspective on physical education. European Physical Education Review, 5(1), 9-30. https://doi.org/10.1177/1356336X990051002

Heft, H. (1989). Affordances and the body: An intentional analysis of Gibson's ecological approach to visual perception. Journal for the theory of social behaviour, 19(1), 1-30. https://doi.org/10.1111/j.1468-5914.1989.tb00133.x

Keele, S. W. (1968). Movement control in skilled motor performance. Psychological bulletin, 70(6p1), 387. https://doi.org/10.1037/h0026739

Kelso, J. S. (1994). The informational character of self-organized coordination dynamics. Human Movement Science, 13(3-4), 393-413. https://doi.org/10.1016/0167-9457(94)90047-7

Kerr, R., \& Booth, B. (1978). Specific and varied practice of motor skill. Perceptual and motor skills, 46(2), 395-401. https://doi.org/10.1177/003151257804600201

Komar, J., Potdevin, F., Chollet, D., \& Seifert, L. (2019). Between exploitation and exploration of motor behaviours: Unpacking the constraints-led approach to foster nonlinear learning in physical education. Physical Education and Sport Pedagogy, 24(2), 133-145. https://doi.org/10.1080/17408989.2018.1557133

Lee, T. D., Swanson, L. R., \& Hall, A. L. (1991). What is repeated in a repetition? Effects of practice conditions on motor skill acquisition. Physical therapy, 71(2), 150-156. https://doi.org/10.1093/pti/71.2.150

Magill, R. A., \& Hall, K. G. (1990). A review of the contextual interference effect in motor skill acquisition. Human movement science, 9(3-5), 241-289. https://doi.org/10.1016/0167-9457(90)90005-X

Merbah, S., \& Meulemans, T. (2011). Learning a motor skill: Effects of blocked versus random practice: A review. Psychologica Belgica, 51(1), 15-48. https://doi.org/10.5334/pb-51-1-15

Newell, K. M., Van Emmerik, R. E. A., \& McDonald, P. V. (1989). Biomechanical constraints and action theory. Human Movement Science, 8(4), 403-409. https://doi.org/10.1016/0167-9457(89)90045-6

Raiola, G. (2014). Motor control and learning skills according to cognitive and ecological dynamic approach in a vision on behaviorism, cognitive, Gestalt and phenomenology theories. Mediterranean Journal of Social Sciences, 5(15), 504-504. https://doi.org/10.5901/mjss.2014.v5n15p504

Renshaw, I., Chow, J. Y., Davids, K., \& Hammond, J. (2010). A constraints-led perspective to understanding skill acquisition and game play: A basis for integration of motor learning theory and physical education praxis?. Physical Education and Sport Pedagogy, 15(2), 117-137. https://doi.org/10.1080/17408980902791586 
Renshaw, I., Araúijo, D., Button, C., Chow, J. Y., Davids, K., \& Moy, B. (2016). Why the constraints-led approach is not teaching games for understanding: A clarification. Physical Education and Sport Pedagogy, 21(5), 459-480. https://doi.org/10.1080/17408989.2015.1095870

Renshaw, I., \& Chow, J. Y. (2019). A constraint-led approach to sport and physical education pedagogy. Physical Education and Sport Pedagogy, 24(2), 103-116. https://doi.org/10.1080/17408989.2018.1552676

Schmidt, R. A., \& Wrisberg, C. A. (2008). Motor learning and performance: A situation-based learning approach. Human Kinetics.

Schmidt, R. A., Lee, T. D., Winstein, C., Wulf, G., \& Zelaznik, H. N. (2018). Motor control and learning: A behavioral emphasis. Human Kinetics.

Swinnen, S. P., Schmidt, R. A., Nicholson, D. E., \& Shapiro, D. C. (1990). Information feedback for skill acquisition: Instantaneous knowledge of results degrades learning. Journal of Experimental Psychology: Learning, Memory, and Cognition, 16(4), 706. https://doi.org/10.1037/02787393.16.4.706

Tomporowski, P. D., McCullick, B., Pendleton, D. M., \& Pesce, C. (2015). Exercise and children's cognition: The role of exercise characteristics and a place for metacognition. Journal of Sport and Health Science, 4(1), 47-55. https://doi.org/10.1016/j.jshs.2014.09.003

Warren, W. H. (2006). The dynamics of perception and action. Psychological review, 113(2), 358. https://doi.org/10.1037/0033-295X.113.2.358

Wolpert, D. M., \& Kawato, M. (1998). Multiple paired forward and inverse models for motor control. Neural networks, 11(7-8), 1317-1329. https://doi.org/10.1016/S0893-6080(98)00066-5

\section{(9) $(\Theta \Theta \Theta$}

This work is licensed under a Attribution-NonCommercial-NoDerivatives 4.0 International (CC BY-NC-ND 4.0). 